\title{
Cartografías de la ciudad nocturna a través del Big Data
}

Cartographies of nightscapes using the Big Data

Mar Santamaria-Varas

Escola Tècnica Superior d'Arquitectura de Barcelona, Universitat Politècnica de Catalunya - BarcelonaTech (UPC)

Mar Santamaria Varas cuenta con una amplia experiencia en proyectos urbanos y de paisaje que combina con su actividad docente e investigadora, basada en la representación del apoyo urbano a través de los Sistemas de Información Geográfica, de la visualización de datos o los nuevos medios audiovisuales. Es profesora asociada del Departamento de Urbanismo y Ordenación del Territorio (UPC) y del Máster de Restauración de Monumentos (UPC). Ha participado como tutora en numerosos workshops internacionales (École Architecture de Lyon, Architectural Association Visiting School Barcelona).

mar.santamaria.upc@gmail.com

ORCID ID 0000-0002-7384-6707

\section{Pablo Martinez-Diez}

Pablo Martínez Díez se dedica al diseño de objetos y espacios, participando en diversos proyectos arquitectónicos, artísticos y de comisariado con el objetivo de generar un diálogo crítico sobre el papel de la iluminación a través de la práctica profesional, la enseñanza y la investigación. Ha sido reconocido por su trayectoria en varias ocasiones (Idda Excellence Awards, ArtFad 2012, Mooi Award 2012, Artsponsor, Injuve, Philips LUMEC ). Es profesor asociado del Centro Universitario de Diseño de Barcelona BAU (UVIC) y profesor invitado del Máster de Restauración de Monumentos (UPC), del Máster de Lighting Design (UPC School), del Grado de Diseño de Interiores y del Curso de especialización en Iluminación de espacios (IED).

pablomartinezdiez@gmail.com

ORCID ID 0000-0001-7285-9197

\section{Resumen}

La visualización de datos se ha convertido en una herramienta clave para el pensamiento y el diseño urbano utilizada para explicar las relaciones que se establecen entre los ciudadanos y su entorno. Nuestro objetivo es explorar el potencial de las técnicas de representación mediante el desarrollo de cartografías digitales que nos permitan asignar geometría al Big Data urbano. 
A través del proyecto atNight, que utiliza el análisis y la visualización de datos para establecer una posible interpretación del paisaje nocturno urbano, queremos generar también un modelo de intervención que desvele los posibles paisajes ocultos detrás de lo visible.

\section{Palabras clave}

Big data, cartografía, SIG, iluminación, diseño, visualización de datos.

\section{Abstract}

\section{Cartographies of nightscapes using the Big Data}

Data visualization has emerged as a key tool in the thinking of urban design used to explain the relationship between citizens and their environment. We aim to explore the potential of techniques representing the city image by developing digital cartographies that enable us to assign geometry to the Big Data. By means of the atNight project, which uses analysis and data visualization to establish a possible interpretation of nightscapes, we seek to generate a model of intervention which reveals the possible landscapes hidden behind the visible.

\section{Keywords}

Big data, cartography, GIS, lighting, design, data visualization.

Recibido 2013-12-29 Aceptado 2014-01-24

"Basta pensar en los focos iluminando encima de todas las torres y desde todas las aeronaves, en la variedad de colores que proyectarán. [...]

Desde Venus y Marte no darán crédito a sus ojos y no lograrán reconocer ya la antigua faz de la tierra.

Quizás entonces la gente acabe por vivir más de noche que de día."

Paul Scheerbart, La Arquitectura de cristal.

\section{EL PLANEAmiento del PAISAJE NOCTURNO}

La iluminación de las ciudades ha sido durante décadas una tarea altamente compleja, supeditada a las limitaciones tecnológicas del momento, que solamente profesionales especializados en la ingeniería de estos sistemas podían comprender y, por lo tanto, diseñar. Nuestras ciudades aún hoy distan mucho de los paisajes oníricos imaginados por Scheerbart (1998). En su ensayo la Arquitectura de cristal, la metrópolis contemporánea mostraba su auténtico rostro al caer el sol mediante los rayos de la luz artificial que 
construían una percepción ilusoria de este territorio, también artificial, que es la ciudad. Actualmente, nuestras calles nocturnas han sido, en el mejor de los casos, diseñadas sorteando las limitaciones de la tecnología, reduciendo el impacto ambiental del consumo eléctrico, procurando no arrojar luz al cielo, tratando de proporcionar intensidades homogéneas a lo largo de los viarios y conteniendo los abusos lumínicos que algunos pocos realizan para imponer su posición y privilegio bajo el manto de la noche. Si bien existen buenos ejemplos europeos que tratan de regular y ordenar esta situación, atendiendo no solamente a la técnica sino a una necesaria complejidad del resultado estético -como son el plan de iluminación de Roma elaborado por Terzi (2001) o los planes para Gant y Amberes de Antico (2011) y los de Narboni (2012) en París-, podemos afirmar que la situación anteriormente descrita se ajusta perfectamente a la gran mayoría de áreas urbanas y muy exactamente a la ciudad de Barcelona, sobre la cual trata el estudio descrito a continuación, atNight.

El paisaje nocturno barcelonés ${ }^{6}$ es fruto de un conjunto de normativas que ignoran cómo es percibida la ciudad. Dichas regulaciones delimitan consumos (jerarquizados por relevancia viaria) y atienden a los usos estipulados por el catastro (genéricos e imprecisos) sin contemplar un análisis más profundo de la complejidad de la noche. Percibimos la Barcelona diurna como un resultado del paso de la historia, con persistencias temporales que construyen nuestra memoria como son los monumentos, arquitecturas y otros signos de identidad colectiva, a la par que la mirada se desplaza de forma continua sobre la piel de los edificios para poderse posar sobre aquellos elementos que el ciudadano decida. Por el contrario, la Barcelona nocturna está formada por permanencias y vacíos, es decir, se configura como un paisaje discontinuo que obliga a dirigir la mirada del observador hacia aquellos lugares más iluminados. Éstos ya no son los hitos de la memoria: sucursales bancarias, concesionarios de coches, hoteles, centros comerciales ensombrecen tanto las fachadas de la ciudad que de día nos arropan como también muchos de los espacios públicos tratados con homogeneidad indiferente al uso y a su población. Si el espacio público de Barcelona es referente para otras metrópolis, sigue siendo una tarea pendiente cómo éste se comporta al caer la noche.

\footnotetext{
${ }^{6}$ A lo largo de este artículo, se utiliza el vocablo paisaje para referirse a la relación estética que se establece entre el observador y su entorno de acuerdo con Berque (2008) y Maderuelo (2005). El término paisaje nocturno se ajusta al carácter eminentemente visual y efímero de la organización de la ciudad de noche.
} 
Somos animales diurnos; generalmente la mayoría de nosotros trabajamos de día pero utilizamos el tiempo nocturno como momento de socialización, ocio y encuentro personal. La noche es el intervalo en el cual encontrar a familia y amigos, el espacio en el que conocemos a los extraños y también cuando la soledad se hace presente. Sin embargo, esta ciudad existe desprovista de la memoria que como sociedad hemos conservado, expuesta a los constantes incumplimientos de las escasas normativas de iluminación ${ }^{7}$. El paisaje urbano que nos contextualiza no está en manos de la ciudadanía. Como enuncia Berque (2008) "el paisaje debe ser un entorno en el que nos reconocemos, no tan solo nosotros en él sino él en nosotros". Debemos, por tanto, tomar conciencia de la existencia de estas dos ciudades, de estas dos percepciones de la misma Barcelona que se desdobla como si tuviese una doble vida tal y como afirma Keppes (1967), una bajo la luz del sol y otra bajo los faros de los coches.

Cómo esta ciudad se relaciona la una con la otra, la del día con la de la noche, es uno de los puntos principales del diseño de los paisajes nocturnos. Estas dos realidades deberán de aprender a coexistir, siendo una misma materia con distintas impresiones. Sirva de metáfora la ciudad imaginaria de Valdrada de los cuentos de Calvino (2000), construida a orillas de un lago, cuya imagen se reflejaba en la superficie espejada del agua. Sus habitantes sabían que cada una de sus acciones era a su vez ésta y la imagen de su reflejo claro y limpio sobre el lago. Pero tal y como cuenta la historia, las imágenes a veces aumentan el valor de las cosas y a veces los niegan, dando como resultado una imposible simetría. Estas dos ciudades vivían continuamente mirándose la una a la otra, y sin embargo no se querían.

La ciudad proyecta dos imágenes, una diurna y otra nocturna, donde esta última se define en relación con la primera, como extensión, reflejo o traslación. Existe una dependencia entre ambas a pesar de que sus usos sean distintos e incluso sus habitantes hayan cambiado. Son dos ciudades que comparten fragmentos de un mismo escenario. En este sentido, la comprensión del actual paisaje nocturno urbano será el primer paso para operar sobre su diseño. La imagen de la ciudad ${ }^{8}$, aunque pueda ser explicada

\footnotetext{
${ }^{7}$ La ordenación del paisaje nocturno en Barcelona queda regulada por el Reglamento Electrotécnico de Baja Tensión (REBT) y la normativa municipal de paisaje urbano.

${ }^{8}$ La imagen de la ciudad y The view from the road de Lynch $(1998,1964)$ representan una aproximación seminal al estudio visual del entorno urbano. En el primero, la percepción de los habitantes a través de sendas, bordes, barrios, nodos e hitos configura una imagen global de la ciudad a través de imágenes individuales y sus relaciones. En el segundo, las secuencias obtenidas a través del movimiento desvelan estructuras territoriales en clave paisajística.
} 
como un collage urbano, no tiene nada de azaroso tal y como corrige Barba (1982) sobre las investigaciones de Gordon Cullen (1974). No se trata de una imagen sin narración sino que responde a múltiples motivos, ocultos durante el día, que actúan simultáneamente y que se hacen visibles durante la noche. El análisis de este paisaje nocturno no tan solo deberá analizar la piel de las ciudades, como diría Solà-Morales (2008) a la relación física que establecen los ciudadanos con el entorno urbano, sino que además deberá buscar aquello que visualmente no podemos percibir a causa de la oscuridad.

Acciones, usos, desplazamientos y actividades configuran las relaciones que conforman la ciudad de noche aunque escapan a nuestra mirada. Si Maderuelo (2005) completa la anterior definición de paisaje como "una mirada intencionada y concreta que se construye entre nosotros (sujetos) y nuestro entorno", deberemos entender el paisaje nocturno tanto como lo que vemos como aquello que bajo la oscuridad no podemos ver, lo oculto y lo intangible. Un paisaje construido, por tanto, por presencias y ausencias, éstas últimas no entendidas como vacíos en la malla de lo visible sino como la base en la que lo visible se sustenta. Tal y como Nogué (2007) describe las geografías de la invisibilidad, a través de la ontología de lo visible de Merleau-Ponty (1975), existe una dependencia de lo visible con lo no visible.

\section{LA CARTOGRAFÍA NOCTURNA DE LA CIUDAD}

La investigación que aquí se presenta ha tratado de desarrollar herramientas de representación, establecer metodologías de análisis cualitativo y aportar casos de estudio para la realización-análisis de cartografías nocturnas de las ciudades contemporáneas.

Tal como apunta Azúa (2004) al referirse a la evolución de la representación del hecho urbano, citando a Walter Benjamin, que indicó la necesidad de utilizar nuevas herramientas de representación como la fotografía o el cine para describir la metrópolis del siglo XX, por contraposición con la descripción literaria propia de la era industrial (Dickens y Londres, Balzac y París, Galdós y Madrid), la ciudad contemporánea deberá encontrar herramientas propias que le permitan describir la complejidad creciente. Formada por tramas viarias pero también por redes de datos, formas y comportamientos. Vuelve a ser esencial redibujar nuestras ciudades explorando los instrumentos que mejor nos permitan capturar su constantemente nueva configuración. 
La ciudad nocturna que permanece invisible, oculta a la sombra de las farolas, es el objetivo de nuestra representación. Para ello será necesario, si bien no podemos verla, detectarla, escucharla a través de otros estímulos. En este contexto, vemos como una oportunidad rastrear y analizar los datos georreferenciados que los ciudadanos y la administración depositan en Internet cuando hacen uso de la ciudad, ya sea compartiendo experiencias en una red social o bien informaciones generadas por los miles de sensores que monitorizan la gestión de los distintos servicios urbanos.

Esta línea de investigación, basada en los datos urbanos, está hoy en constante crecimiento y transformación, a la vez que las metodologías de análisis están aún definiéndose y generando experiencias de uso que no podrán ser validadas hasta el paso de algunos años. Esta información forma parte del denominado Big Data -es decir, la manipulación de grandes conjuntos de datos-, que aumenta sin cesar y cuyo potencial mayor está todavía por descubrir. Durante los primeros años de la existencia de Internet se especuló sobre la aparición de nuevas relaciones espaciales, en las que los lugares desaparecían o simplemente pasaban a fusionarse los unos con los otros, dando paso a una deslocalización de la información y de la misma idea de lugar, un contexto propiciado por la aún reciente publicación de los No Lugares de Augé (1993) que utilizaba como uno de los ejemplos más significativos de su hipótesis los espacios de tránsito. Así es cómo se vislumbraba la existencia de una red de calles formada por Internet que se sobreponía a la red de las calles reales. Una interconexión entre informaciones y lugares que nada tenía que ver con su representación en el espacio real. Sin embargo, tal como constata Castells (2004), el espacio informativo de los flujos se acopla con el paisaje físico de la ciudad: Internet conecta geográficamente oficinas, negocios, residencias y servicios.

Coincidiendo con esta corriente de pensamiento, las aproximaciones iniciales a nuestra investigación atNight publicadas en Mas Context (2012), que utilizaron como punto de análisis las imágenes alojadas en Flickr con metadatos georreferenciados, mostraron que la información contenida en la red deslocalizada podía ofrecer una visión muy precisa del mundo real. Este primer artículo demuestra cómo se puede redibujar el trazado de las calles de la ciudad a través de las imágenes almacenadas en Flickr (los lugares más vistos revelan por negativo la ciudad no visible), además de representar la trama urbana a través del uso que sus ciudadanos le dan a lo largo de las horas y 
revelar cuáles de todas esas imágenes pueden componer una cartografía de la identidad de Barcelona.

A partir de esta primera verificación, las cartografías resultantes del proyecto han tratado de dar forma al Big Data geolocalizado. Para ello, ha sido imprescindible la utilización de sistemas de información geográfica (SIG), que nos han permitido vincular el dato con el territorio, para volver a dibujar la forma de la ciudad. Si durante el último siglo las herramientas SIG han evolucionado radicalmente, ya sea por la cantidad de satélites rastreando la superficie terrestre como por la facilidad con la que los datos que éstos producen se pueden manipular -gracias a softwares abiertos como Qgis-, no ha habido una transformación en sus objetivos de uso. Seguimos cartografiando la topografía y las divisiones del territorio (países, calles y parcelas) con unos instrumentos con una sofisticación y un potencial tal que nos invitan a pensar que la cartografía deberá evolucionar tanto en el modo de representar como también en aquello que se representa.

Por otro lado, durante los últimos diez años se han llevado a cabo numerosas experiencias que han tratado de utilizar la cartografía (sin hacer uso de las herramientas SIG) como documento para el empoderamiento ciudadano o la reflexión urbana. A título de ejemplo, encontramos la Cartografía del estrecho de Gibraltar realizada por Hackitectura e Indymedia Estrecho entre otros (Lama, 2006), las cartografías realizadas de forma colaborativa por González (2004) junto a los vecinos en el diseño de la Plaza Lesseps de Barcelona, el mapa elaborado para el Fórum 2004 de las Culturas de Barcelona [2004] denunciando los intereses económicos en la ciudad por los patrocinadores y los mapas de exploración del barrio del Poble Nou, también en Barcelona, realizados por Rotorrr [2013]. Estos mapas anuncian el uso de la cartografía como herramienta para el empoderamiento ciudadano, la toma de decisiones colectiva, la explicación de la ciudad, y la exploración sensorial y subjetiva del territorio.

La propuesta de trabajo del equipo atNight, consistente en la visualización cartográfica de datos urbanos de Barcelona, enlaza con los trabajos de otros grupos de investigación entre los cuales destaca el Senseable City Lab [2013] del Masachusets Institute of Technology, desde donde surgen las propuestas más sugerentes acerca de la representación del Big Data. También se toma como referencia directa las cartografías Local vs Tourist elaboradas por Eric Fischer (Nix, 2013), en las cuales se analizan las imágenes alojadas en los servidores de la red social Flickr, clasificadas según la procedencia del usuario 
ya sea éste un habitante de la ciudad o un turista (según un algoritmo definido para tal fin). Este ejemplo, que ofrece en una única representación las distintas percepciones de la ciudad por estos dos grupos demográficos, es sin duda uno de los primeros paradigmas del uso del denominado Social Data, datos provenientes de la utilización de las redes sociales digitales. Finalmente, se han utilizado en muchos casos aproximaciones gráficas, y las herramientas que las generan, aportadas por el equipo de representación cartográfica Stamen Design (2013), cuyas estrategias ponen el foco tanto en la resolución del problema como en la aplicación de métodos que permiten un control gráfico minucioso y ágil de los resultados.

\subsection{METODOLOGÍA DE TRABAJO}

La elaboración de las cartografías de la investigación atNight se ha dividido en distintas fases desde la obtención de datos, a su posterior almacenamiento, análisis, representación y publicación.

La obtención de datos especuló con el posible trabajo a partir de cuatro ámbitos temáticos y sus respectivas fuentes de información: energía, estructura visual, movilidad y actividad. En este aspecto, cabe mencionar la imposibilidad de acceder a informaciones tan relevantes como el consumo eléctrico de la ciudad, un dato que sin duda nos permitiría analizar de una manera precisa la actividad urbana nocturna. Este dato así como otros muchos relacionados con la energía (agua, gas) no han sido cedidos por las empresas correspondientes, argumentando problemas con la privacidad de los datos o alegando que dichos datos no existen. La misma argumentación ha sido empleada por departamentos de la administración pública, entre los cuales el Departamento de alumbrado público de Barcelona, al solicitar las mediciones luxométricas sobre la calzada realizadas durante el 2012. Claramente, en todos estos casos, justificaciones poco convincentes y ante las cuales se encuentra cualquier investigador que emplea los datos para sus trabajos.

De ahí, la necesidad de utilizar, en primer lugar, datos del servicio Open Data de la ciudad de Barcelona como bases cartográficas y otras informaciones urbanas que también pueden ser adquiridas por otras vías, como por ejemplo el estado del tráfico. En segundo lugar, se ha tenido acceso a datos de algunas empresas privadas (o con participación pública) mediante convenios de cesión, tales como las frecuencias de paso de los transportes públicos o el número de pasajeros, cedidos por Transports Metropolitans de Barcelona y el Área Metropolitana de Barcelona. 
Por último, la fuente de datos más interesante del proyecto ha resultado la captura propia de datos geolocalizados de Internet, ya sea a través de redes sociales abiertas donde los usuarios comparten la información de forma pública (Twitter, Flickr, Panoramio, Instagram) u otros servicios online como MYTAXI, que emplea información de geoposicionamiento de la flota de taxis de Barcelona publicada online ${ }^{9}$. El período de captura ha variado en función de la fuente de datos desde la totalidad de histórico de informaciones (Flickr) hasta lapsos de varios meses (Twitter, Instagram, MYTAXI) o anualidades completas (transporte público). Se han desarrollado varios códigos propios para la captura de datos alojados en Internet ${ }^{10}$, empleando Python como lenguaje de programación por la gran compatibilidad con muchas librerías cartográficas. Los códigos han realizado tareas simples de conexión a servidores de datos y de rascado de datos scrapping con BeautifulSoup en aquellas ocasiones en que la información no se intercambiaba en formatos fácilmente parseables como JSON o XML.

Los datos obtenidos han sido almacenados en distintos formatos en función de su complejidad. De este modo, se han empleado archivos de texto separado por comas [*.CSV], archivos shapefile generados mediante la librería para Python PYSHP de Joel Lawhead, bases de datos sencillas como SQLITE y SPATIALITE y, finalmente, el almacenaje general de todas las informaciones en bases de datos POSTGIS. La multiplicidad de formatos de almacenaje se debe a una adaptación al tipo de servidor con el que hemos trabajado en cada momento así como a la flexibilidad para la prueba rápida de distintos códigos.

El análisis realizado y como se ha abordado la minería de datos [data mining, en inglés] sobre las informaciones acumuladas es quizás uno de los puntos más singulares de la investigación. La representación del Big Data requiere de una simplificación de la cantidad ingente de información a mostrar con el objetivo de encontrar patrones de similitud en zonas no continuas de la trama urbana y de definir los límites de estas áreas. Para ello, son comunes herramientas de análisis estadístico que buscan trazar una simplificación sobre la gran cantidad de datos para luego representarla. En nuestro caso, el procedimiento ha evitado este paso intermedio de simplificación de la información, arrojando los datos capturados en bruto sobre los planos a dibujar

\footnotetext{
9 El análisis de Big Data nos permite extrapolar, gracias al gran número de interacciones obtenidas, patrones y comportamientos a nivel urbano. Si bien el uso de las tecnologías digitales no ha arraigado manera uniforme entre los distintos segmentos de población, el crecimiento exponencial de estos avances y la calidad y cantidad de la información proporcionada justifica la existencia de pioneras líneas de investigación académicas.

10 Publicados en el repositorio de código del proyecto https://github.com/atnightmaps.
} 
con el fin de construir cartografías con millones de puntos y sin reducción de resolución.

Así, hemos empleado sistemas visualmente intuitivos que nos permiten descubrir con mucha facilidad patrones de comportamiento $y$ zonas semejantes. Hemos utilizado las herramientas de representación y las convenciones gráficas para el análisis y comunicación de la información. Se ha trabajado la asignación de color según valores (utilizando escalas de colores complementarios o bien similares), se ha empleado la opacidad para desvelar agrupaciones de datos (para poder interpretar el solapamiento de puntos), o se han empleado también mezclas de color entre elementos con criterios de multiplicación o aclarado de los valores RGB dependiendo de la intencionalidad de la interpretación de los datos. También se han agrupado los datos según la forma urbana a la que pertenecen, asignándoles una vía o bien una manzana, para comprender si el dato, por ejemplo una interacción en Twitter, pertenece al ámbito público de la calle o bien al privado de un local o una vivienda. En algunos casos, las informaciones cartografiadas han sido además filtradas mediante palabras clave, es decir, mostrando solamente aquellos datos que contuviesen alguna palabra concreta (como el nombre de la ciudad).

Para concluir, la información ha sido publicada on-line siguiendo estándares habituales. Se ha configurado un sencillo servidor de teselas visualizadas mediante la librería de código Leaflet, empleando el sistema de coordenadas WGS84 y la proyección Pseudo Mercator ${ }^{11}$, así como un servidor WMS para la consulta y utilización de los datos en bruto por otros usuarios y equipos de investigación; todas ellas herramientas ampliamente utilizadas por usuarios especializados en sistemas de información geográfica y desarrolladores de software.

\subsection{LAS CARTOGRAFÍAS}

Las cartografías elaboradas han tratado de mostrar la diversidad de los datos según la franja horaria a la que pertenecen. Se han filtrado los datos por horas, se les ha asignado una entidad geométrica, se han representado y se han cruzado con otros datos, permitiendo ofrecer un contraste para la interpretación del dato.

\footnotetext{
${ }^{11}$ La publicación electrónica de los materiales adopta el sistema de referencia geodésico WGS84 Pseudo Mercator por su compatibilidad con Google Maps y Open Street Maps.
} 
A continuación se describen las cartografías elaboradas, así como los principales datos empleados para su elaboración y los criterios de representación empleados para el análisis.

\subsubsection{ESTRUCTURA VISUAL}

\section{IMAGEN E IDENTIDAD}

Constelación Barcelona y Barcelona es Barcelona quieren ser una primera aproximación a la estructura del paisaje nocturno de la ciudad de Barcelona a través de las informaciones localizadas alojadas en las redes sociales Flickr, Instagram y Twitter. Constelación Barcelona construye una imagen que se aproxima a la vista por satélite donde los puntos, que representan los lugares más registrados por los usuarios, dibujan los principales elementos de la forma urbana de la ciudad según una jerarquía de intensidad que pone en primer plano las áreas con mayor densidad de registros.

En una segunda lectura, la cartografía Barcelona es Barcelona, resultado del filtrado de los datos anteriores que contienen la palabra Barcelona, especula sobre los lugares de la identidad y la memoria desde los sitios turísticos (parque Güell, La Rambla y la Sagrada Familia) a los espacios próximos (la plaza de nuestro barrio, la calle de nuestra casa o la del bar de la esquina), dándonos la clave para entender la interdependencia entre la forma urbana y su percepción por parte de los ciudadanos. Los habitantes miran y registran los monumentos importantes, las calles principales, las plazas pero también valoran otros sitios anónimos, poco conocidos, fruto de geografías personales.

\section{DÍA Y NOCHE}

Barcelona noche y día, representación obtenida a partir de fotografías geolocalizadas alojadas en las redes sociales Flickr e Instagram filtradas por hora (en azul la noche, en naranja el día), nos demuestra que durante las horas diurnas la estructura visible y el soporte físico de la ciudad coinciden, siendo reconocibles tanto el centro de la ciudad como sus arquitecturas y espacios público característicos. En cambio, durante la noche, la continuidad entre los diversos puntos de la ciudad queda interrumpida y la forma urbana es dibujada a partir de múltiples focos.

De la misma manera, a través de la cartografía Singularidad vs. Identidad generada a partir de las informaciones georreferenciadas alojadas en las redes sociales Instagram y Twitter filtradas por manzana- constatamos la presencia 
de áreas homogéneas con una identidad mayoritariamente diurna o nocturna, de fragmentos urbanos mixtos en los cuales día y noche se alternan y de puntos centrales cuya percepción se mantiene del día a la noche (siendo lugares siempre presentes en el imaginario urbano).

\section{CIUDAD VISIBLE, CIUDAD VIVIDA}

La estructura visible de la ciudad, sintetizada en las representaciones anteriores, se compara con la percepción de los ciudadanos a través de la experiencia. Así, en las cartografías Sentimiento Barcelona/Noche $y$ Sentimiento Barcelona/Día - obtenidas a partir de los mensajes georreferenciados de la red social Twitter filtrados por sentimiento $y$ clasificados por hora- se ha querido abstraer una Barcelona que, sin línea de costa, calles ni puntos de referencia, es perfectamente identificable a través de la actividad urbana. Una urbanidad que, a lo largo del día, se traslada nuevamente del centro a la periferia, convirtiéndose esta última en el lugar de los sentimientos positivos propios del tiempo de la socialización más allá de las horas productivas del día. La ciudad visible desaparece para dar cabida a la ciudad vivida.

\subsubsection{MOVILIDAD}

La serie de cartografías de movilidad quiere hacer visibles patrones de comportamiento propios del transporte público y privado con relación a la eficiencia y densidad de la trama urbana. En primer lugar, Movimiento vs. Densidad quiere ilustrar cómo se corresponden el espacio de la vialidad y el lugar de lo privado. Así, el movimiento (capa generada a partir de los desplazamientos geolocalizados de MYTAXI), se contrapone con la densidad de población por manzana (OpenDataBcn) para cuestionar si las áreas más servidas, las calles principales y las intersecciones importantes son soporte del habitar. En segundo lugar, la representación Taxi noche y día (elaborada con los mismos datos de recorridos de taxi que la anterior), busca expresar a través de los flujos de movilidad la síntesis de la forma urbana para identificar ciertas interferencias entre los flujos de movimiento de noche y de día (azul y naranja respectivamente). Nuevamente, de día, los recorridos del taxi perfilan una ciudad homogénea mientras que de noche aparecen nuevos órdenes jerárquicos dentro de la trama viaria. En tercer lugar, Bicing noche y día visualiza el tiempo de la parada y del intercambio y la actividad que generan alrededor de las estaciones de la red de Bicing de Barcelona. Estas áreas de influencia, dibujadas a partir de la disponibilidad de bicicletas por hora, 
construyen un patrón que, por contigüidad, diferencia los lugares de mayor o menor relevancia dentro de la topografía de la ciudad (noche y día se superponen o se alternan en cada caso).

\subsubsection{USO Y ACTIVIDAD}

La última pareja de cartografías, analiza el paisaje nocturno desde su uso. Por un lado, Nocturnidad, que representa las actividades georreferenciados del servicio web Google Places filtradas por tipo de establecimiento y hora del día, se hace eco de la doble vida de la ciudad, una bajo la luz del sol y otra bajo las faros de los coches, los carteles luminosos publicitarios, las luces que emanan del interior de los edificios y la que es proyectada por las farolas, ofreciendo un "espectáculo luminoso singular, fortuito y accidental" (Keppes, 1967). Las luces anaranjadas de sodio de haz difuso que transforman los colores, los haces de luz estrechos que el mismo tiempo que realzan ocultan por el desmesurado contraste, la luz de los escaparates que invade las aceras son hoy los elementos que dan forma a la noche.

Por el otro, la representación Fiesta, Food \& Safety, cartografía actividades lúdicas y espacios bajo vigilancia a través de los mismos establecimientos georreferenciados del servicio web Google Places. Se constata que la noche se ha convertido en el tiempo del ocio urbano y de la vida social más allá de sus diversos significados. Desde el encuentro simbólico entre el hombre y la naturaleza al tiempo del miedo y del peligro, la noche ha encarnado los valores de lo diabólico y del pecado por contraposición con el día, lugar de la victoria y del bien. En este momento de lo prohibido y animal es donde todavía hoy suceden el crimen y el robo pero también la fiesta, la ilusión, los sueños, el carnaval y los excesos.

\section{PRIMERAS CONCLUSIONES}

A partir de las cartografías elaboradas, se extraen unas primeras conclusiones generales. En primer lugar, podemos afirmar que la ciudad se puede representar mediante los datos obtenidos a través de sensores urbanos o de las redes sociales. Los elementos arquitectónicos singulares o bien aquellos espacios públicos de mayor representatividad aparecen fielmente resaltados a través de la multitud de puntos de las interacciones que estos lugares producen sobre el Big Data. Existe, por lo tanto, una relación directa entre el espacio de la ciudad y los datos que ésta genera, permitiendo lecturas que no solamente hablen de la forma geométrica urbana sino también de su estructura 
de valor. Efectivamente, existen singularidades dentro de la trama urbana, generadas por distintos factores, que se escapan a lecturas más canónicas y que se refieren a la interpretación subjetiva que los ciudadanos realizan del entorno.

Se muestra como evidencia clara que la ciudad a lo largo del día no tiene un comportamiento homogéneo. Si comparamos la densidad de los datos en distintos puntos veremos que es diferente; si comparamos el mismo valor en igual ubicación según franjas horarias, constatamos que también varía. Ello comporta que podamos describir cómo la ciudad adquiere distintos patrones por zonas y por lapsos de tiempo. Esta hipótesis, hasta el momento apuntada, deviene ahora mesurable $y$, en consecuencia, permite establecer comparaciones y evaluaciones objetivas.

Las cartografías realizadas también arrojan luz sobre algunos temas muy específicos sobre el planeamiento urbano de la ciudad. En primer lugar, se verifica que los lugares de actividad diurna se corresponden en mayor grado con su estructura visual. Por ejemplo, si se compara la actividad de Twitter (breves mensajes de texto que expresan opiniones, estados de ánimo o informan de actividad) frente a Instagram, Panoramio o Flickr (en los que el usuario muestra aquello que ve), se demuestra una mayor sincronía de día que de noche. Es decir, aquello que vemos está más directamente relacionado con los lugares de la acción diurna; sin embargo, de noche, estas dos capas de actividad se separan. En efecto, la estructura visible de noche se corresponde con aquellos espacios urbanos mayormente iluminados al tiempo que áreas dominantes durante el día, desaparecen al caer el sol. Si en lugar de atender a los puntos de mayor concentración, nos fijamos en la distribución o uniformidad de los valores existentes en zonas intermedias entre grandes concentraciones, observaremos una mayor cantidad de puntos en éstas últimas. Este fenómeno nos indica que de noche, si bien las concentraciones masivas de puntos están ligadas a las zonas de gran iluminación, el resto de la trama contiene muchos otras zonas que nos hablan del uso disperso, no concentrado, que los habitantes hacen de la ciudad nocturna.

Por otra parte, en las cartografías se observan grandes comportamientos de la ciudad, influenciados probablemente por la topografía del territorio pero también por el nivel económico de los distintos barrios. Por ejemplo, el análisis del uso del Bicing en Barcelona nos muestra cómo muchos desplazamientos que se producen durante el día, desparecen de noche, dando a entender un cambio en el medio de transporte o haciendo referencia al hecho de que ciertos 
barrios concentran más desplazamientos de noche que de día. De la misma manera, si analizamos los recorridos de los ciudadanos a través de transporte privado individual (taxis), se nos muestra una trama urbana diurna, que se mantiene bastante uniforme, por contraposición a una jerarquía viaria nocturna cuyas calles se redibujan en función de la intensidad variable (mientras que el alumbrado urbano se mantiene uniforme).

En definitiva, nos encontramos ante una trama urbana que se reorganiza de noche, que traslada sus focos de intensidad y actividad, que modifica sus viarios, a lo largo de los cuales cambian los flujos de tránsito. Los usos que jerarquizan y ordenan la trama son otros, y los ciudadanos utilizan esta ciudad de un modo distinto. Los lugares en los que estos se reúnen, encuentran, celebran y conocen son otros a los del día. Entre ellos, Paseo de Gracia que concentra no solamente un mayor tráfico sino también una gran cantidad de interacciones en redes sociales durante el día, desciende drásticamente al caer la noche, como también la población que lo habita, ya que apenas tiene residentes. A pesar de ello, sigue concentrado el mayor número de edificios iluminados, a la par que unas amplias aceras profusamente alumbradas pero que de noche apenas son transitadas. La observación subjetiva de este hecho queda objetivamente representada en los documentos realizados.

Estas cuestiones son claves en el contexto actual de rediseño de nuestras ciudades en el cual, el consumo eléctrico derivado de la iluminación nocturna de la ciudad, ya sea el del viario como el de los monumentos, debe ser responsabilidad y decisión de todos. Cabe tener en cuenta que los excesos de algunos pueden penalizar al conjunto de la sociedad [tal y como procede el protocolo de Kyoto] y que el uso que hacemos de los recursos energéticos debe ser consensuado, dado que éstos son limitados. Tampoco iluminar la fachada de un edificio puede ser una decisión individual ya que, en un entorno de oscuridad, ésta modela el escenario de nuestra sociedad de un modo determinante. Tanto por la afectación sobre los recursos energéticos como por la incidencia que la iluminación pueda tener en la construcción de la memoria histórica o la invención de nuevos símbolos sobre el paisaje nocturno deberemos utilizar herramientas que nos permitan trasladar estas decisiones de diseño del ámbito de lo subjetivo a lo objetivo para poder ser evaluadas por la ciudadanía.

En conclusión, el estudio aquí presentado tiene carácter de prototipo, existiendo grandes y necesarios objetivos de mejora. Por un lado, deben aumentarse los periodos de análisis, con mayor cantidad de datos, para poder 
analizar de forma diferenciada las distintas estaciones del año. Entendemos que, como cualquier estudio cartográfico que pretenda medir y asignar valor a aquello representado, necesita de distintas iteraciones periódicas del proceso a través de las cuales se perfeccionarán las metodologías y se apreciarán las variaciones y transformaciones del caso de estudio (Barcelona) a lo largo del tiempo. Por otro lado, será esencial reproducir las mismas cartografías en distintas ciudades y comprender su capacidad para abordar distintos contextos urbanos.

Es por todo esto que consideramos indispensable ahondar en esta línea de investigación. Hay que recordar que el trabajo de nuestros proyectistas urbanos muchas veces debe realizarse únicamente a partir de informaciones cartográficas tradicionales (pendientes, parcelas, inventario urbano, etc.) y de estadísticas demográficas a nivel de barrio. Poder comprender como se comporta la ciudad en la interacción con el ciudadano, cómo surgen lugares de concentración, cómo nos movemos por las calles y cómo, en definitiva, utilizamos la ciudad y el territorio, es crucial para adaptar las ciudades a las transformaciones sociales constantes. Esta información cartográfica puesta al alcance de la sociedad deberá ofrecer una herramienta de empoderamiento ciudadano, que permita tomar decisiones individuales y colectivas a través de documentos que describan cómo es realmente la ciudad que habitamos.

\section{REFERENCIAS}

ANTICO, S. (2011). "The light of Mechelen and Antwerpen". En: Luce, núm. $1 / 2011$.

AUGÉ, M. (1993).Los "No lugares": espacios del anonimato: una antropología de la sobremodernidad. Barcelona: Gedisa.

AZÚA, F. (2004). "La necesidad y el deseo". En: AZÚA, F. et al. La arquitectura de la no-ciudad. Pamplona: Universidad Pública de Navarra.

BARBA, R. (1982). "Paisaje. Entre el análisis del entorno y el diseño del espacio exterior". En: Quaderns d'Arquitectura i Urbanisme, núm. 153.

BERQUE, A. (2008). La pensée paysagère. Paris: Archibooks+Sautereau Éditeur.

CALVINO, I. (2000). Las ciudades Invisibles. Madrid: Siruela.

CASTELLS, M. (2004). La città delle reti. Vicenza: Marsilio.

CULLEN, G. (1974). El paisaje urbano: tratado de estética urbanística.

Barcelona: Ed. Blume. 
GONZÁLEZ, I. (2004). La plaça Lesseps. En: Quaderns d'arquitectura i urbanisme, nún. 240.

KEPPES, G. (1967). "Notas sobre expresión y comunicación en el paisaje urbano". En: LLOYD, R. et al. La metrópoli del futuro. Barcelona: Seix Barral. LYNCH, K. (1964). The view from the road. Cambrige: The MIT Press. LYNCH, K. (1998). La imagen de la ciudad. Barcelona: Gustavo Gili. MADERUELO, J. (2005). El Paisaje. Génesis de un concepto. Madrid: Abada. MERLEAU-PONTY, M. (1975). Fenomenología de la percepción. Barcelona: Península.

NARBONI, R. (2012). Les éclairages des villes: Vers un urbanisme nocturne. Suisse: Infolio.

NIX, M. (2013). Visual Simplexity. Frankfurt: entwickler.press.

NOGUÉ, J. (2007). "Territorios sin discurso". En: Revista Eria, núm. 73. PÉREZ DE LAMA, J. (2006). Devenires cíborg: arquitectura, urbanismo y redes de comunicación. Sevilla: Universidad de Sevilla.

POBLE NOW: zona ex-obrera en obras. [sitio web]. 2013. Barcelona: Rotorrr. [Consulta: 20 diciembre 2013]. Disponible en:

http://rotorrr.org/exploraciones_poblenow/ SANTAMARIA-VARAS, M.; MARTINEZ-DIEZ, P. (2012). "Atnight visions trough data". En: Mas Context, núm. 15.

SCHEERBART, P. (1998). La arquitectura de cristal. Valencia: Colegio Oficial de Aparejadores y Arquitectos Técnicos de Murcia.

SENSEABLE CITY LAB MIT [sitio web]. 2013. Cambridge: MIT. [Consulta: 20 diciembre 2013]. Disponible en: http://senseable.mit.edu/ SOLÀ-MORALES, M. (2008). De cosas urbanas. Rotterdam: NAI. STAMEN DESIGN [sitio web]. 2013. San Francisco: Stamen Design. [Consulta: 20 diciembre 2013]. Disponible en: http://stamen.com TERZI, C. (2001). Los planes de luz. Milán: Editoriale Domus. 